\title{
Atrioventricular Block in Acute Coronary Syndromes
}

\author{
Safae Harrak*, Fatima Chikhi, Btissam Fellat, Mohammed Cherti \\ Cardiology B Department. Mohammed V University in Rabat, Morocco
}

*Corresponding Author: Safae Harrak, Cardiology B Department. Mohammed V University in Rabat, Morocco

\begin{abstract}
Introduction: Atrioventricular (AV) block is a common complication of acute coronary syndrome. Our aim is to analyze the prevalence and characteristics of this conductive disorder and to describe the epidemiological, clinical and paraclinical aspects of these patients.
\end{abstract}

Material and Methods: We conducted a prospective study on patients with acute coronary syndrome complicated by atrioventricular block at the cardiology B department in Rabat from July 2017 to June 2019.

Results: Thirty patients complicated with AV block out of 407 (7.37\%). AV block is documented on admission in 20 patients $(66.67 \%)$ and develops during hospitalization in 10 patients $(33.33 \%)$. The mean age of the patients is 61.9 years $( \pm 7.72)$. The sex ratio is 1.5 with 18 men $(60 \%)$ and 12 women (40\%).

The ECG diagnosed a ST segment elevation in 27 patients (90\%) and a ST segment depression in 3 patients (10\%). Signs of ischemia are mainly localized in the inferior territory (70\%). Third-degree atrioventricular block is the most frequent (63\%) followed by second-degree AV block Mobitz type I (17\%), Mobitz type II $(13 \%)$ then first-degree (7\%). AV block is identified on admission in 20 patients (70\%) and appears during hospitalization in 10 patients (30\%). This conductive disorder regresses in 18 patients (60\%) even in the absence of revascularization. The mean regression time was 4.52 days \pm 5.6871 and it persists in 12 patients (40\%), 5 of whom died. Intra-hospital mortality is $16.67 \%$.

Conclusion: AV block is often high-grade and occurs in the context of inferior myocardial infarction. It is frequently recorded on the initial ECG and spontaneously regresses even in the absence of revascularization. Nevertheless, a pacemaker implantation may sometimes be necessary regardless of the territory of ischemia.

Key words: atrioventricular block, acute coronary syndrome, inferior territory, anterior territory

\section{INTRODUCTION}

Acute coronary syndrome (ACS) results from a sudden reduction in coronary blood flow and most often occurs as a result of a ruptured atheroma plaque with the formation of thrombus. This lack of irrigation can cause transient dysfunction or irreversible damage to the conduction system [1, 2]. The site of coronary occlusion determines the site of conduction blockage. On the other hand, the conductive disorder may result from vagal hyperactivity in the first few hours of myocardial ischemia, which may induce a transient slowing of cardiac conduction. Other contributing factors may include metabolic and hydro electrolytic disturbances and the effect of treatment [2].

The aim of our study is to evaluate the prevalence and characteristics of atrioventricular block during the course of acute coronary syndrome and to describe the epidemiological, clinical and paraclinical aspects of these patients.

\section{MATERIALS AND METHODS}

We conducted a prospective study of patients with acute coronary syndrome (ACS) with or without ST segment elevation complicated by atrioventricular block. This work was carried out in the cardiology B department of the Ibn Sinauniversity hospital in Rabat. The study period was two years; from July 2017 to June 2019.

We included patients in whom the diagnosis of ACS was retained. The occurrence of aatrioventricular block was systematically investigated. Statistical analysis was performed based on the collected and validated data. All variables in the patient database of our study were analyzed.

Quantitative variables were expressed as frequency $(\%)$ and qualitative variables were 
presented as means and standard deviation and/or medians with interquartile ranges. The software used was Epi Info version 3.6 and SPSS version 13.0.

\section{Results}

\subsection{Epidemiological and Demographic Data}

During the study period, 407 patients were hospitalized in our department to manage acute coronary syndrome (ACS). Thirty patients developed atrioventricular block, representing a prevalence of $7.37 \%$ of ACS. The mean age of our study population is 61.9 years $( \pm 7.72)$ (extremes of 48 and 80 years). The sex ratio is 1.5 with 18 men (60\%) and 12 women (40\%).

\subsection{Clinical data}

We had found a personal history of coronary artery disease in 5 patients $(16.7 \%)$. Chest pain

Table 1: Cardiovascular risk factors found as well as the functional signs reported by our patients

\begin{tabular}{|c|c|c|c|}
\hline & & Numberof patients & Percentage $\%$ \\
\hline \multirow{7}{*}{$\begin{array}{l}\text { Cardiovascular } \\
\text { riskfactors }\end{array}$} & Arterial hypertension & 19 & $63.3 \%$ \\
\hline & Diabetesmellitus & 12 & $40 \%$ \\
\hline & Smooking & 18 & $60 \%$ \\
\hline & Dyslipidemia & 21 & $70 \%$ \\
\hline & Obesity & 8 & $26.7 \%$ \\
\hline & Menopause & 8 & $26.7 \%$ \\
\hline & Coronaryheredity & 4 & $13.3 \%$ \\
\hline \multirow[t]{6}{*}{ Functionalsigns } & Typicalchest pain & 21 & $70 \%$ \\
\hline & Atypicalchest pain (epigastralgia) & 9 & $30 \%$ \\
\hline & Dyspnea & 6 & $20 \%$ \\
\hline & Syncope & 7 & $23.3 \%$ \\
\hline & Lipothymia & 6 & $20 \%$ \\
\hline & Vertigo & 1 & $3.6 \%$ \\
\hline
\end{tabular}

\subsection{Paraclinical Data}

The ECG diagnosed ST segment elevation in 27 patients $(90 \%)$ and ST segment depression in 3 patients $(10 \%)$. The electrical signs are mainly localized in the inferior leads $(83 \%)$ with or without abnormalities in the right precordial leads. Third-degree atrioventricular (AV) block represents the most common conductive disorder $(63 \%)$ followed by second-degree AV block Mobitz type I (17\%), Mobitz type II (13\%) then first-degree(7\%).AV block was documented on admission in 20 patients (66.67\%), and developed during hospitalization in 10 patients (33.33\%). Transthoracic echocardiogram was performed in all patients and found segmental wall motion abnormalitiesin 28 patients $(93 \%)$. Left ventricular dysfunction was diagnosed in 11 patients (48\%). Right ventricular dysfunction was noted in 8 patients $(27 \%)$.

\subsection{Therapeutic Management}

As most of our patients were seen outside of the thrombolysis time window, this was only done was the most common symptom reported by our patients. The median time between chest pain and first medical contact is 24 hours (interquartile range 8-96 hours). Table 1 projects the different cardiovascular risk factors found as well as the functional signs reported by our patients. The average systolic blood pressure (SBP) is $120.03 \mathrm{mmHg} \pm 21.88$ (extremes 70$166 \mathrm{mmHg}$ ) and the average diastolic blood pressure (DBP) is 68.03 \pm 13.46 (extremes 45$99 \mathrm{mmHg}$ ). Heart rate (HR) averaged $60.62 \mathrm{c} / \mathrm{min} \pm 23.03$ (extremes $30-114 \mathrm{c} / \mathrm{min}$ ) and cardiogenic shock was found in 4 patients $(13.3 \%)$. Cardiac auscultation revealed a murmur of mitral insufficiency in 2 patients. No signs of right heart failure were found. In addition, pleuropulmonary examination revealed crackles (Killip class II) in 9 patients (30\%). for 6 patients (20\%). We concluded that thrombolysis was successful in only 2 patients. Coronary angiography was performed in 23 patients $(76 \%)$. It found mono-troncularlesionof right coronary artery in 10 patients. Bitroncularlesions were found in 9 patients;lesion of right coronary artery associated with a circumflex lesion in 4 patients and lesion of right coronary artery associated with a lesion of the Left anterior descending arteryin 5 patients. Coronary angioplasty was limited to the culprit lesion and was performed in 13 patients $(56 \%$ of patients undergoing coronary angiography). In the absence of myocardial viability, a revascularization procedure was not performed. Three patients underwent the insertion of a temporary transvenous pacing that was indicated for a syncopal atrioventricular block.

The definitive implantation of a pacemaker was considered in 4 patients before a third-degree AV block in 3 patients and a Mobitz 2 type 2 AV block in 1 patient. 


\subsection{Intra-Hospital Evolution of the AV Block}

The conductive disorder regressed in 18 patients $(60 \%)$ and persisted in 12 patients (40\%). The mean time to spontaneous regression is 4.52 days \pm 5.6871 . Table 2 shows the characteristics of regressive AV block. Table 3 represents the evolution of persistent AV block.

Table2: The characteristics of regressive AV block (number of patients 18)

\begin{tabular}{|l|l|}
\hline & \multicolumn{1}{|c|}{ Number of patients(\%) } \\
\hline Spontaneous regression in no-revascularized patients & $9(50 \%)$ \\
\hline Spontaneous regression before the revascularization procedure & $6(33 \%)$ \\
\hline Immediateregressionafterrevascularization & $1(6 \%)$ \\
\hline Delayed regression after revascularization & $2(11 \%)$ \\
\hline
\end{tabular}

Table3: The evolution of persistent AV block (number of patients 12)

\begin{tabular}{|l|c|}
\hline & Numberof patients(\%) \\
\hline High degree AV block requiring definitive stimulation & $4(33 \%)$ \\
\hline High grade AV block in patients who have progressed to death & $5(42 \%)$ \\
\hline Persistant first-degree AV block & $3(25 \%)$ \\
\hline
\end{tabular}

There were no deaths in the angioplasty group, but we recorded paroxysmal atrial fibrillation that resolved spontaneously in three patients and persistent atrial flutter in which case we couldn't restore a sinus rhythm (failed cardioversion) in one patient. The mortality rate in our series was $16.6 \%$.

\subsection{Follow-Up During Three Months}

Three-month follow-up objectified the regression of first-degree $\mathrm{AV}$ block in three patients. There were no ischemic events or congestive events. The stress echo did not confirm myocardial viability in norevascularized patients.

\section{DISCUSSION}

The prevalence of AV block in our series is close to that observed by Kane AD et al. [26] but remains lower than the study conducted by Hanachiet al. [27] (7.6\%). It most often complicatescoronary syndrome with ST elevation (90\% vs 10\%). Kane $\mathrm{AD}$ et al. have found a percentage of $87.5 \%$ of patients. Studies that specifically analyze the high degree AV block also found the same report [28,29].Male predominance has also been reported [26,30]. While first-degree atrioventricular block was the most frequent in the studies conducted by Kane ADet al. [26] and by Kumar et al.[30], the thirddegree AV block is the most predominant in our study. The enormous delay between the onset of symptoms and revascularization is likely to induce significant and prolonged ischemia. This is likely to severely disrupt atrioventricular conduction and to induce a conductive disorder at this level. It has been observed that atrioventricular block appears more often in cases of inferior myocardial infarction. This finding is also found in the literature when the coronary syndrome involves the inferior wall $[30,31]$. This can be explained by the fact that vascularization of the conduction system is mainly ensured by the right coronary artery.

In the literature, AV block in inferior myocardial infarction occurs early, and it was found during the initial ECG in $66.67 \%$ of our patients. Transient vagal hypertonia at the onset of symptoms is likely to induce this conductive disorder at an early stage. Another reason is the delay in consulting patients, which exposes them to the aggravation of myocardial ischemia. According to Aplin $\mathrm{M}$ et al., conductive disorder that occurs during hospitalization is attributed to anterior territorial ischemia [32]. However, in our series, it occurs in a number of patients with electrical signs of ischemia in the inferior territory. During acute coronary syndrome, there is a release of electrolytes, such as potassium, from the necrotic myocytes that accumulate day by day, as Sclarovsky explains [33]. This rate is significant from 24 hours after the infarction and persists until the fourth day after the acute coronary syndrome [34, 35]. On the other hand, adenosine is also released in large quantities and can accumulate, leading to the appearance of a conductive disorder according to Shah et al. [36]. These chemical disturbances may be the cause of late AV block in our patients.

Another characteristic of our series is often the regressive nature of the conductive disorder even without revascularization (out of time, lack of myocardial viability). The conduction tissue of the AV node has the particularity of being resistant to permanent damage due to ischemia due to several reasons. On the one hand, it has a relatively low metabolic rate with high glycogen reserves. On the other hand, it is characterized 
by the presence of extensive collateral circulation (contribution of the left coronary artery branches in addition to the right coronary) as well as its ability to absorb nutriments and oxygen by diffusion from the surrounding sinus veins [37]. Acute ischemia during the coronary syndrome is capable of temporarily altering the functioning of the conductive fibers, while at the same time, vagal hypertonia gradually lifts during hospitalization and allows the resumption of normal electrical activity.

The occurrence of these conductive disorders is associated with a high mortality rate in the short and long term [38]. According to the study by Vincent auffret et al. [39], high-grade AV block is not directly responsible for the increase in intrahospital mortality but is mainly due to the extent of myocardial ischemia and the mechanical, rhythmic, and hemodynamic complications that result. A multicenter study by kyunghwan et al. [17] concluded that the prognostic impact of high-grade AV block is different depending on the area of ischemia (more deaths in cases of anterior wall myocardial infarction compared to AV block in cases of inferior wall MI). Another study also confirmed this finding [40]. Nevertheless, in our series, all who died had inferior wall MI.

In the presence of a conductive disorder resulting from acute myocardial ischemia, urgent revascularization should be considered. According to the Task Force of the European Society of Cardiology published in 2014 [41], the use of an electro systolic stimulation lead is indicated in cases of high degree AVB or symptomatic intraventricular block that does not regress after successful reperfusion and medical treatment. It should only be considered routinely if chronoscopic positive drugs (isoproterenol, atropine) are insufficient or contraindicated. Implantation of a definitive pacemaker is recommended for conductive disorders that persist despite reperfusion and beyond the acute phase of coronary syndrome.

\section{CONCLUSION}

In our context, AV block is often high grade and occurs in case of inferior wall myocardial infarction. It is frequently recorded on the initial electrocardiogram and regresses spontaneously even in the absence of revascularization. Nevertheless, it can sometimes indicate the implantation of a definitive pacemaker regardless of the territory of ischemia.

\section{REFERENCES}

[1] B. Gorenek et al, «Cardiac arrhythmias in acute coronary syndromes: position paper from the joint EHRA, ACCA, and EAPCI task force, » Europace, vol. 16, p. 11, 2011.

[2] william j. brady jr, md, facep, faaema, richard a. harrigan, faaemb «Diagnosis and management of bradycardia and atrioventricular block associated with acute coronary ischemia,» vol. $19, \mathrm{n}^{\circ} 12$, p. $371-384$, 2001.

[3] TN, James et al .The coronary circulation and conduction system in acute myocardial infarction. Prog Cardiovasc Dis, $\mathrm{n}^{\circ} \% 110$, pp. 410-428, 1968.

[4] Van der Hauwaert LG, Stroobandt R, Verhaeghe $\mathrm{L}$.Arterial blood supply of the atrioventricular node and main bundle. $\mathrm{Br}$ Heart J, n \%134, pp. 1045-1051, 1972.

[5] Raghuveer Dendi, Mark E.Josephson. Conduction Disturbances in Acute Myocardial Infarction. Cardiac Intensive Care (Second Edition), pp. 251-254, 2010.

[6] Frink RJ, James TN. Normal blood supply to the human his bundle and proximal bundle branches. Circulation, vol. 47, $\mathrm{n}^{\circ} 18$, p. 18, 1973.

[7] HJ, Trappe .Tachyarrhythmias, brad arrhythmias and acute coronary syndrome. J Emerg Trauma Shock, vol. 3, $\mathrm{n}^{\circ} 12$, pp. 137-14 2, 2010 .

[8] AL, Mark.The Bezold-Jarisch reflex revisited: clinical implications of inhibitory reflexes originating in the heart. $\mathrm{J}$ Am Coll Cardiol, $\mathrm{n}^{\circ}$ 11, pp. 90-102, 1983.

[9] Come PC, Pitt B .Nitroglycerin-induced severe hypotensionandbradycardia in patients with acute myocardial infarction. Circulation, vol. 54, p. 624-628, 1976.

[10] EM, Antman. Acute myocardial infarction. Heart disease: a textbook of cardiovascular medicine. 5th edition, Philadelphia: WB Saunders: Braunwald E, 1997, p. 1245-1253.

[11] Bhandari AK, Sager PT. Management of periinfarctional ventricular arrhythmias and conduction disturbances. Cardiac arrhythmias: a practical approach., New York: Futura Publishing, 1991, p. 283.

[12] Roberts R, Morris D,PrattC,et al. Pathophysiology, recognition, and treatment of acute myocardial infarction and its complications. Hurst's the heart: arteries and veins., New York: McGraw-Hill: Schlant RC, Alexander RW, et al, editors, 1994.

[13] Baquero GA, Banchs JE,Depalma S,Young SK,Penny-Peterson ED,Samii S Metal. Dofetilide reduces the frequency of ventricular arrhythmias and implantable cardi- overter defibrillator therapies. J Cardiovasc Electrophysiol, vol. 23, p. 296-301, 2012. 
[14] Camm A J, Pratt C M,Schwartz P J,Al-Khalidi H R,Spyt M J ,Holroyde M Jetal. Azimi- Lide post Infarct surVival Evaluation (ALIVE) Investigators. Mortality in patients after a recent myocardial infarction: a randomized, placebo-controlled trial of azi- milide using heart rate variability for risk stratification. Circulation, vol. 109, p. 990-996. , 2004.

[15] Kosuge M, Kimura K, Ishikawa T, Nakatogawa T, Saito T, Okuda J, et al. Clinical features of patients with reperfused inferior wall acute myocardial infarction complicated by early complete atrioventricular block. Am J Cardiol, vol. 88, n%110, p. 1187-1191, 2001.

[16] Simons GR, Sgarbossa E, Wagner G, Califf RM,Topol EJ,Natale A. Atrioventricular and intraventricular conduction disorders in acute myocardial infarction: a reappraisal in the thrombolytic era. Pacing Clin Electrophysiol, vol. 21, p. 2651-2653, 1998.

[17] Kyung Hwan Kim, et al. Differential Clinical Implications of High-Degree Atrioventricular Block Complicating ST-Segment Elevation Myocardial Infarction according to the Location of Infarction in the Era of Primary Percutaneous Coronary Intervention. Korean Circ J., vol. 46, n \%13, p. 315-323, 2016.

[18] Adgey AA, Geddes JS, Mulholland HC, Keegan DA, Pantridge JF.Incidence, signi cance, and management of early bradyarrhythmia compli- cating acute myocardial infarction,» Lancet, $\mathrm{n}^{\circ} \% 17578, \mathrm{p}$. 1097-1101, 1968.

[19] Webb SW, Adgey AA, Pantridge JF. Autonomic disturbance at onset of acute myocardial infarction. Br Med J, vol. 3, $\mathrm{n}^{\circ} \%$ 15818, p. 89-92, 1972.

[20] Feigl D. AshkenazyJ, KishonY .Early and late atrioventricular block in acute inferior myocardial infarction. J Am Coll Cardiol, vol. 4, p. 35-38, 1984.

[21] Bezzina CR, Pazoki R, Bardai A, Marsman RF, de Jong JS, Blom MT et al.Genome-wide association study identifies a susceptibility locus at $21 \mathrm{q} 21$ for ventricular fibrillation in acute myocardial infarction. Nat Genet, vol. 42, p. 688-691, 2010.

[22] [Manz M, Mletzko R, Jung W, Lüderitz B .Electrophysiological and haemodynamic effects of lidocaine and ajmaline in the management of sustained ventricular tachycardia. Eur Heart J, vol. 13, p. 1123-1128, 1992.

[23] Køber L, Torp-Pedersen C, McMurray JJ, Gøtzsche O, Lévy S, Crijns $\mathrm{H}$ et al. Dronedarone Study Group. Increased mortality after dronedarone therapy for severe heart failure. N Engl J Med, vol. 358, p. 2678-2687, 2008.
[24] Lewin RF, Sclarovsky S, Strasberg B. Right axis deviation in acute myocardial infarction: clinical significance, hospital evolution, and long-term follow-up. Chest, vol. 85, pp. 489496, 1988.

[25] Hindman MC, Wagner GS, Jaro M, et al .The clinical significance of bundle branch block complicating acute myocardial infarction: II. Indications for temporary and permanent pacemaker insertion. Circulation, vol. 58, p. 689-699, 1978.

[26] kane ad, ndiaye $\mathrm{mb}$, diao $\mathrm{m}$ et al.Auriculoventricular blocks during acute coronary syndrome (SCA): about 24 cases. Dakar med, vol. 56, p. 1, 2011.

[27] Hanachi N, Derbel F, Ben Ismail M .Le blocs auriculo-ventriculaires à la phase aiguë de l'infarctus du myocarde. Evolution et pronostic. A propos de 90 cas,» Ann CardiolAngéiol, vol. 37, pp. 137-142, 1988.

[28] [Gang UJ, Hvelplund A, Pedersen S, Iversen A, Jøns C, Abildstrøm SZ, et al. High-degree atrioventricular block complicating ST-segment elevation myocardial infarction in the era of primary percutaneous coronary inter-vention. Europace, vol. 14, n¹11, p. 1639-1645, 2012.

[29] Hwang IC, Seo WW, Oh IY, Choi EK, Oh S.Reversibility of atrio-ventricular block according to coronary artery disease: results of a retrospective study. Korean Circ J, vol. 42, ${ }^{\circ}$ \%112, p. 816-822, 2012.

[30] Kumar V, Goyal S, Kumar S, Mirnal. Study of Conduction Blocks in Acute Myocardial Infarction. Ann. Int. Med. Den. Res. 2018; 4(2):ME20-ME24.

[31] Majumder AA, Malik A, Zafar A. Conduction disturbances in acute myocardial infarction: incidence, site wise relationship and the influence of in-hospital prognosis. Bangladesh Med Res Counc Bull, vol. 22, n \%12, pp. 7480, 1996.

[32] Aplin M, et al.Prognostic importance of complete atrioventricular block complicating acute myocardial infarction. American $\mathbf{J}$ Cardiol, vol. 92, $\mathrm{n}^{\circ}$ 17, p. 853-856, 2003.

[33] Sclarovsky S, Strasberg B, Hirshberg A, Arditi A, Lewin RF, Agmon J.Advanced early and late atrioventricular block in acute inferior wall myocardial infarction. Am Heart J, vol. 108, $\mathrm{n}^{\circ}$ 11, pp. 19-24, 1984.

[34] [34] Jackrel J, Miller JA, Schechter FG, Minkowitz S, Stuckey JH .Atrioventricular conduction following ligation of the anterior septal artery in the dog. An electrocardiographic, histopathology and histochemical study. Am J Cardiol, vol. 25, $\mathrm{n}^{\circ}$ \%15, pp. 552-561, 1970.

[35] Hackel DB, Wagner G, Ratliff NB, Cies A, Estes EH Jr .Anatomic studies of the cardiac conducting system in acute myocardial 
infarction. Am Heart J, vol. 83, n $\% 11$, pp. 77$81,1972$.

[36] [Shah PK, Nalos P, Peter T. Atropine resistant post infarction complete AV block: possible role of adenosine and improvement with aminophylline. American Heart Journal, vol. 113, $\mathrm{n}^{\circ} 11$, p. 194, 1987.

[37] Anatomy, histology, and pathology of the cardiac conduction system-Part V.Anatomy, histology, and pathology of the cardiac conduction system-Part V. Clin Cardiol, vol. 16, p. 565-569, 1993.

[38] Cheng S, Keyes MJ, Larson MG. Long-term outcomes in individuals with prolonged PR interval or first-degree atrioventricular block. JAMA, vol. 301, n \%124, p. 2571-2577, 2009.

[39] Vincent Auffret, et al .High-degree atrioventricular block complicating ST segment elevation myocardial infarction in the contemporary era. British Cardiac Society, vol. 102, n 11 , pp. 40-49, 2015.

[40] Uffe Jakob Ortved Gang et al. High-degree atrioventricular block complicating ST-segment elevation myocardial infarction in the era of primary percutaneous coronary intervention,» Europace, vol. 14, p. 1639-1645, 2012.

[41] Gorenek B, Blomström Lundqvist C, Brugada Terradellas J, Camm AJ, Hindricks G, Huber K, Kirchhof P, Kuck KH, Kudaiberdieva G, Lin T, Raviele A, Santini M, Tilz RR, Valgimigli M, Vos MA, Vrints C, Zeymer U, Lip GY, Potpara T, Fauchier L, Sticherling C, Rof. Cardiac arrhythmias in acute coronary syndromes: position paper from the joint EHRA, ACCA, and EAPCI task force. Europace, vol. 16, $\mathrm{n}^{\circ} 111$, pp. 1655-1673, 2014.

Citation: Safae Harrak. Fatima Chikhi. Btissam Fellat. Mohammed Cherti. Atrioventricular Block in Acute Coronary Syndromes. ARC Journal of Cardiology. 2020; 6(2): 01-06. Doi:doi.org/ 10.20431/2455-5991. 0602001.

Copyright: (C) 2020 Authors. This is an open-access article distributed under the terms of the Creative Commons Attribution License, which permits unrestricted use, distribution, and reproduction in any medium, provided the original author and source are credited. 